\title{
Predictors of coronary heart disease and death in NIDDM: The Diabetes Intervention Study experience
}

\author{
M . H anefeld ${ }^{1}$, H . Schmechel ${ }^{2}$, U . Schwanebeck ${ }^{1}$, J . L indner ${ }^{3}$, The D IS G roup \\ ${ }^{1}$ Medical Faculty C. G. Carus, Technical University Dresden, Germany \\ ${ }^{2}$ District Hospital Weimar, Germany \\ ${ }^{3}$ District Hospital Chemnitz, Germany
}

Non-insulin-dependent diabetes mellitus (NIDDM) is associated with an excessive incidence of coronary heart disease and a reduction in life-expectancy of 510 years $[1,2]$. This is mainly due to a clustering of established risk factors such as hypertension, hypertriglyceridaemia, low HDL-cholesterol, high concentration of small dense LDL and smoking.

The Diabetes Intervention Study (DIS) is a prospective multicentre trial of newly detected middleaged NIDDM patients classified as diet-controlled at entry into the study [3]. As previously reported [4] $15.2 \%$ of the patients suffered from myocardial infarction and $19.8 \%$ had died after 11 years' follow-up.

The odds ratio for myocardial infarction compared to the general population for males at the age of 50 59 was 2.7 , and for females 6.2 after 5 years' followup [3]. Cardiovascular diseases (32\%) were the major cause of death although clinical manifestations of this disease group represented an exclusion criterion and the average age at entry was only 46.7 (CI 46.3-47.0) years. The endangering of NIDDM is indicated by the excessive all-cause mortality rates in the young age group. The DIS patients at the age of 36-45 years showed an odds ratio of 5.1 for males and 7.0 females respectively in comparison to the general population.

In multivariate analysis age, blood pressure, triglycerides and smoking at entry were significant independent risk factors for the incidence of myocardial infarction in the 11-years' follow-up. In a striking parallel, the same parameters together with female sex and postprandial blood glucose were independent predictors of all-cause mortality.

Corresponding author: Professor M. Hanefeld, Universitätsklinik der Tu Dresden, Institut und Poliklinik für klinische Stoffwechselforschung, Fetscherstrasse 74, D-01307 Dresden, Germany

A bbreviations: NIDDM, Non-insulin-dependent diabetes mellitus; IRS, insulin-resistance syndrome.
As shown by Reaven and Greenfield [5] and Ferrannini and DeFronzo [6] a multifaceted syndrome with hyperinsulinaemia, hypertriglyceridaemia/low HDL and hypertension exists in NIDDM. This could explain why established risk factors such as hypercholesterolaemia and hypertension bear a two to fourfold higher risk for cardiovascular mortality than in non-diabetic subjects [7]. So far, little information exists on the epidemiology of this syndrome in representative cohorts of NIDDM patients. Evaluating the data from DIS, this paper tries to answer the following two questions: (1) What is the prevalence of insulin resistance/hyperinsulinaemia syndrome (IRS) in DIS patients? (2) What is the impact of this syndrome on coronary heart disease and mortality?

\section{Subjects and methods}

Details of patient recruitment, study design, baseline data and methods have been previously published [3, 4]. Insulin measurement [8], HDL-cholesterol and ApoB were included at the 5 years' follow-up examination. Patients treated with insulin in the meantime $(n=48)$ were excluded.

In total 760 patients underwent a 75 -g oral glucose tolerance test with insulin determination at baseline and after $2 \mathrm{~h}$. IRS was defined as follows: fasting serum insulin greater than $111.2 \mathrm{pmol} / \mathrm{l}$ ( >1 s for healthy control subjects) triglycerides greater than $2.3 \mathrm{mmol} / \mathrm{l}$ and blood pressure greater than 140/ $90 \mathrm{~mm} \mathrm{Hg}$ and /or treatment with antihypertensive drugs. Endpoints were ischaemic heart disease (Minnesota Codes 1.3, 4.1-4.3 or 5.1-5.3 or 7.1 in resting ECG), myocardial infarction (clinical or codes 1.1 and/or 1.2) and all-cause mortality in the 6 to 11 year follow-up period.

\section{Results and Discussion}

As shown in Table 1 in about every second patient fasting hyperinsulinaemia was found 5 years after diabetes detection. The average insulin level was 
Table 1. Prevalence of hyperinsulinaemia (IRI > $111.3 \mathrm{pmol} / \mathrm{l}$ ) in DIS: 5 year follow-up

\begin{tabular}{lllll}
\hline & & $(\mathrm{n})$ & \multicolumn{2}{l}{$\begin{array}{l}\text { Percent with } \\
\text { hyperinsulinaemia }\end{array}$} \\
\hline Sex & male & 433 & 45 & N.S. \\
& female & 327 & 47.1 & N.S. \\
Age & $40-50$ & 279 & 44.4 & N.S. \\
(years) & $50-60$ & 481 & 46.8 & N.S. \\
Blood pressure & $>140 / 90$ & 232 & 38.8 & $<0.05$ \\
(mmHg) & $140 / 90-160 / 95$ & 137 & 44.5 & $<0.05$ \\
& $>160 / 95$ & 374 & 51.1 & $<0.05$ \\
Body mass index & $\mathrm{F}<24 ; \mathrm{M}<25$ & 125 & 26.4 & $<0.01$ \\
(kg/m $\left.{ }^{2}\right)$ & $\mathrm{F} \leq 26 ; \mathrm{M} \leq 27$ & 141 & 41.8 & $<0.01$ \\
& $\mathrm{~F}>26 ; \mathrm{M}>27$ & 484 & 52.1 & $<0.01$ \\
Triglycerides & $<2.3$ & 508 & 40.6 & $<0.01$ \\
$($ mmol/l) & $\geq 2.3$ & 222 & 57.7 & $<0.01$ \\
\hline
\end{tabular}

significantly higher than in age and weight-matched non-diabetic control subjects $(n=53) ; 90$ vs 120 $\mathrm{pmol} / \mathrm{l}(\mathrm{p}<0.01)$.

The prevalence of the IRS was as follows: males $44.4 \%$, females $49.5 \%$, age $40-50$ years $40.7 \%$, 5060 years $50.8 \%$.

Patients with IRS exhibited ischaemic ECG changes in 26.8 vs $5.6 \%$ in patients without $(p<0.01)$. This result was obtained despite losses due to fatal myocardial infarction in the prephase.

The incidence rates for myocardial infarction and death $(\mathrm{n} / 1000)$ were as follows: myocardial infarction in IRS 134.1 vs 68.6 ( $p$ NS), death in IRS 159.8 vs 47.2 $(p=0.011)$.

In multivariate analysis we were able to compare 34 subjects with newly diagnosed myocardial infarction vs 209 without ECG changes at the 11-year follow-up investigation. The following 7 of 16 variables were revealed as independent risk factors: male sex, blood pressure, $2 \mathrm{~h}$ postprandial blood glucose, fasting insulin, total cholesterol, apoB and smoking. For death ( $\mathrm{n}=69$ vs 398 survivors) the following independent risk factors were identified: male sex, BMI, blood pressure, smoking, fasting and postprandial blood glucose and HDL-cholesterol. The percentage of "grouped" cases correctly classified was however low: $66.1 \%$ for myocardial infarction and $68 \%$ for death.

In conclusion IRS was found to be a major cause of coronary heart disease and death in NIDDM.

\section{References}

1. Pyörälä K, Laakso M, Uusitupa M (1987) Diabetes and atherosclerosis: an epidemiologic view. Diabetes Metab Rev 3: 463-524

2. Panzram G (1987) Mortality and survival in type 2 (non-insulin-dependent) diabetes mellitus. Diabetologia 30: 123131

3. Hanefeld M, Fischer S, Schmechel H et al. (1991) Diabetes Intervention Study Multi-Intervention Trial in Newly Diagnosed NIDDM. Diabetes Care 14: 308-317

4. Hanefeld M, Fischer S, Julius U et al. DIS Group (1996) Risk factors for myocardial infarction and death in newly detected NIDDM: the Diabetes Intervention Study, 11year follow-up. Diabetologia 39: 1577-1583

5. Reaven G, Greenfield M (1981) Diabetes hypertriglyceridemia. Evidence for three clinical syndromes. Diabetes 30: 66-75

6. Ferrannini F, DeFronzo RA (1991) Insulin resistance. A multifaceted syndrome responsible for NIDDM, obesity, hypertension, dyslipidemia, and atherosclerotic cardiovascular disease. Diabetes Care 14: 173-194

7. Stamler J, Vaccaro O, Neaton J, Wentworth D, for the Multiple Risk Factor Intervention Trial Research Group (1993) Diabetes, other risk factors, and 12-year cardiovascular mortality for men screened in the multiple risk factor intervention trial. Diabetes Care 16: 434-449

8. Gottschling D, Ziegler M, Wilke W, Michael W (1974) Radioimmunoassay von Plasma Insulin-methodenkritische Untersuchungen. Radiobiol Radiother 15: 91-97 